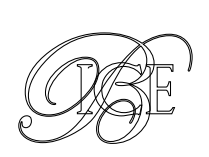

\title{
POLÍTICA COMERCIAL ESTRATÉGICA DE LA ADMINISTRACIÓN COMERCIAL ESPAÑOLA Un caso de éxito
}

Este artículo pretende evaluar y constatar el éxito en una de las líneas de acción que la Administración comercial española introdujo en el primer Plan Integral de Desarrollo de Mercados (PIDM) para el Consejo de Cooperación del Golfo (CCG): la apuesta por el desarrollo de las relaciones económico-comerciales con el Sultanato de Omán y la consiguiente apertura de una Oficina Económica y Comercial.

Para ello se presentará la metodología estratégica que permitió identificar las zonas de interés estratégico para las cuales España elaboró los PIDM, y se hará una referencia sintética a las actuaciones que la Administración comercial ha llevado a cabo en el Sultanato en desarrollo de esta estrategia, para finalmente analizar la evolución económica y comercial entre ambos países. El lector podrá observar cómo los resultados parecen corroborar el acierto en la elección y el planteamiento.

Palabras clave: Administración comercial, política comercial, estrategia, PIDM, Omán, diversificación. Clasificación JEL: F00, F10, F59, H00.

\section{Introducción}

Tal y como describieron Pérez Raposo y Cerno (2011), en aras de «lograr un eficiente rendimiento de los recursos destinados a la promoción exportadora, el sector público debe elegir unos mercados prioritarios sobre los que concentrar sus acciones, y, en este sentido, en 2004 España definió su propia metodología de selección de mercados

*Subdirector Adjunto de la Subdirección General de Estudios y Evaluación de Instrumentos de Política Comercial. Dirección General de Política Comercial y Competitividad. Secretaría de Estado de Comercio.

Versión de septiembre de 2017. prioritarios en el seno de la Secretaría de Estado de Turismo y Comercio, del Ministerio de Industria, Turismo y Comercio (MITYC). A partir de la selección realizada, en diciembre de 2004, se pusieron en marcha los Planes Integrales de Desarrollo de Mercado (PIDM), firmados entre el MITYC y la Confederación Española de Organizaciones Empresariales (CEOE), en los países denominados prioritarios. A diferencia de otras iniciativas de programas de acción comercial que surgieron en paralelo en países de la Unión Europea (UE), la metodología española ampliaba el campo de aplicación para la promoción tanto de exportaciones como de inversiones. De este $D$ 
modo, la puesta en marcha de este programa ha buscado impulsar las exportaciones $y$ diversificar su patrón de comercio, así como potenciar la presencia de empresas españolas en los mercados con mayor potencial para ello».

En este artículo se pretende hacer repaso y evaluación de lo acontecido en torno a una de las acciones que emanaron de aquel planteamiento estratégico, la apuesta de la Administración comercial española por desarrollar las relaciones con un país como el del Sultanato de Omán, una de las líneas de actuación de uno de estos Planes Integrales de Desarrollo de Mercado, el del Consejo de Cooperación del Golfo (CCG), y entre cuyas medidas adoptadas conllevó la apertura de una Oficina Económica y Comercial en la ciudad de Mascate.

Para ello, en este artículo, primero se hará mención y se resumirá el análisis y la investigación que se llevó a cabo en el seno de la Administración comercial para determinar los países o áreas en los cuales se iba a enfocar/ priorizar la acción comercial y de promoción de inversiones españolas. A continuación, y como resultado de aquella investigación, se hará referencia a la adopción del Plan Integral de Desarrollo de Mercado del CCG a finales de 2008 y a la apertura casi simultánea de la Oficina Económica y Comercial de España para Omán, para después pasar a sintetizar las acciones llevadas a cabo en ese país a resultas de este planteamiento estratégico.

Por último, en este artículo se hace una evaluación tanto de la evolución del país de Omán (buscando contrastar las previsiones iniciales resultantes del análisis de la Administración) como de la evolución de las relaciones comerciales y económicas bilaterales en comparación con el periodo previo.

\section{La metodología de la Administración comercial española para la determinación de los mercados prioritarios}

\section{La Subdirección General de Análisis y} Estrategia de la Secretaría de Estado de Turismo y Comercio hizo público en $2005^{1}$ la metodología mencionada para la selección de mercados prioritarios, en la cual justificaba la necesidad de hacer un replanteamiento estratégico o al menos un análisis de posicionamiento de la especialización española ante los continuos cambios que se estaban experimentando en el panorama comercial internacional (aparición de nuevos competidores, apertura y liberalización de mercados, progreso en las comunicaciones y en los medios de transporte, etcétera). Así, la metodología que se proponía para identificar y clasificar a los mercados con potencial para la internacionalización de las empresas españolas se desarrolló a partir de un conjunto de indicadores cuantificables (relativos a la evolución de las exportaciones españolas y de la inversión española en el exterior, así como a la situación económica, política y de cualquier otro tipo que se considere relevante de los diferentes países en los que pueden actuar las empresas españolas), que permitían la comparación homogénea de un grupo extenso de países, para los cuales se construyeron además unos mapas de situación (de exportaciones e inversiones).

Como se avanzaba entonces, «la aplicación de aquella metodología presenta una serie de ventajas. En primer lugar, se basa en criterios cuantificables que permiten realizar $D$

Subdirección General de Análisis y Estrategia (2005). «Metodología de la Secretaría de Estado de Turismo y Comercio para la selección de mercados prioritarios", publicado en el Boletín Económico de ICE, n. $\stackrel{\circ}{2} .836$. 
comparaciones sobre una base homogénea. En segundo lugar, los resultados obtenidos pueden actualizarse de manera dinámica. Por último, permite la evaluación y control de los resultados obtenidos en el caso de que se apliquen planes específicos de internacionalización en determinados países».

El total de indicadores utilizados entonces fue de veinticinco, que se clasificaron en tres grandes grupos: atractivo mercado, fuerza competidora y posición inversora. El primer grupo, denominado atractivo mercado, incluyó todos aquellos indicadores relativos a características económicas y de cualquier otro tipo, que en principio señalan si un país es lo suficientemente atractivo para que las empresas foráneas dirijan hacia él sus exportaciones o sus inversiones en el exterior. En este grupo se incluyeron doce indicadores, repartidos a su vez en cinco subgrupos: tamaño de mercado, crecimiento de mercado, factores económicos, riesgos comerciales y políticos, y otros factores.

Al segundo grupo, fuerza competidora, pertenecieron los indicadores que reflejan la posición de las exportaciones españolas en el país, así como cualquier otra variable que podía mostrar una ventaja competitiva de las empresas españolas en ese mercado. Este grupo se componía de seis indicadores, divididos a su vez en cuatro subgrupos: posición española en el país, contribución del país a las exportaciones españolas, dinamismo exportador y otros factores.

En el tercer y último grupo, posición inversora, se incluyeron los indicadores que reflejaban la posición de las inversiones de las empresas españolas en el país y las posibles ventajas competitivas de España para las inversiones españolas en ese mercado. A este grupo pertenecieron seis indicadores, divididos en cuatro subgrupos: posición española en el país, contribución del país a las inversiones exteriores españolas, dinamismo inversor y otros factores.

Como se ha señalado, a partir de estos indicadores se elaboraron unos mapas que permitieron diferenciar grupos de países y más específicamente aquellas áreas en las que teniendo un elevado atractivo de mercado la fuerza competidora española resultaba reducida o al menos tenía amplio margen de mejora.

\section{Los PIDM: el PIDM del Golfo y la apertura de la Oficina Económica y Comercial de España en Omán}

Como resultado de aquel ejercicio analítico, la Administración comercial española identificó los mercados de alto potencial para la internacionalización de la empresa española, y, como se ha adelantado, en colaboración con la Confederación Española de Organizaciones Empresariales (CEOE), se pusieron en marcha los Planes Integrales de Desarrollo de Mercado (PIDM), en un primer momento para nueve países: Estados Unidos, Brasil, México, Marruecos, Argelia, Rusia, China, India y Japón.

Estos planes de actuación, en consecuencia, tienen por objetivo fomentar la presencia de empresas españolas, consolidando la de las que ya están en estos mercados; coordinando los instrumentos de promoción tanto de la Administración comercial como de otras entidades, como la CEOE, y creando un marco de coordinación estable que permita focalizar las relaciones económicas y comerciales con las autoridades económicas de cada país. Cada plan incluye, además, una definición de los sectores objetivo del marco institucional bajo el cual se habrían de desarrollar las visitas institucionales, los diferentes acuerdos $\triangleright$ 
internacionales (convenios para evitar la doble imposición, convenios de protección recíproca de intereses, etcétera), así como de las acciones de promoción, información y formación dirigidas a las empresas españolas.

Ante la amplia aceptación y apoyo de este enfoque y planteamiento, se decidió en 2007 ampliar el número de países e incluir a Turquía y Corea del Sur, para los cuales se prepararon otros respectivos PIDM, y en 2008 se configuró el primer, y de momento único, PIDM definido, referido a un área aduanera que trasciende a un solo país, el del Consejo de Cooperación del Golfo (CCG), que engloba a Arabia Saudí, Emiratos Árabes Unidos, Catar, Kuwait, Omán y Bahréin.

Este PIDM del CCG, que en su primera versión se articuló para el periodo 2009-2011, se marcaba como objetivos: (i) un crecimiento medio de las exportaciones a los países del Golfo entre 5 y 7 puntos superior al crecimiento de las exportaciones españolas totales, (ii) conseguir aumentar en más de 700 las empresas exportadoras a los países del Golfo, (iii) incrementar la cuota de mercado de nuestras exportaciones, (iv) participar en los más de dos billones de dólares en proyectos licitados, (v) aprovechar la coyuntura de gran liquidez y demanda de infraestructuras, (vi) fomentar los acuerdos y joint-ventures entre empresas de España y del CCG, (vii) estimular la implantación de empresas españolas en países de la zona aprovechando la liberalización y apertura, (viii) promover la imagen de España, (ix) dar a conocer a las empresas españolas la realidad del Golfo (sectores de mayor crecimiento, proyectos de interés, formas de implantación, instrumentos de apoyo públicos), y (x) animar a las empresas españolas a participar activamente en los proyectos en marcha en la zona y establecerse. Asimismo, dicho PIDM hace ya una priorización de sectores tanto para el comercio de bienes (material y equipos eléctricos, equipamiento doméstico y de colectividades, maquinaria, componentes de automoción, materiales de construcción y agroalimentarios) como para el comercio de servicios (ingeniería, arquitectura, logística, franquicias, servicios financieros, tecnologías de la información y de las comunicaciones (TIC), y escuelas de negocios) y para licitaciones o inversiones (agua, redes eléctricas, energías renovables, ferrocarriles, aeropuertos, construcción y operadores hoteleros).

Enfocados en los objetivos citados, y teniendo en cuenta los sectores prioritarios mencionados, los PIDM (tanto de la versión inicial como de las que les siguieron) fueron articulando el refuerzo y énfasis de la zona en materia de apoyo institucional, medidas de acceso al mercado, de promoción e imagen, de apoyo financiero, de formación e información, y de atracción de inversiones en esta zona. La primera medida de refuerzo institucional que comprendía este PIDM hacía referencia a la apertura de una Oficina Económica y Comercial de España en Omán. Efectivamente, en septiembre de 2008 tenía lugar la toma de posesión del primer consejero económico y comercial de la Embajada de España en Omán.

\section{La actuación de la Administración comercial española desde la aprobación del PIDM y el establecimiento de relaciones}

No es tanto el objetivo de este apartado del artículo el de enumerar por separado y detalladamente todas las actuaciones llevadas a cabo desde 2008 por la Administración comercial española (ya que desbordaría los límites $\triangleright$ 
aprobados para este artículo y conllevaría una enumeración que complicaría su lectura), sino que lo que se pretende es dar fe de esa especial apuesta de la Administración comercial española por el fortalecimiento de las relaciones con este país en el marco del PIDM del Golfo aprobado en base al planteamiento estratégico descrito.

En consecuencia, se puede sintetizar señalando, en primer lugar, que, durante este periodo, se han producido en torno a veinte viajes y visitas bilaterales institucionales de altos cargos donde sin ninguna duda destaca el viaje oficial en abril de 2014 de SM el Rey Juan Carlos, acompañado de los ministros de Defensa, Fomento e Industria, Energía y Turismo; así como de los secretarios de Estado de Comercio y de Asuntos Exteriores y del secretario general de Infraestructuras. Asimismo, cabe destacar que los secretarios de Estado de Comercio en esta época han realizado cuatro visitas adicionales al país. Pero estas visitas $\mathrm{y}$ viajes han sido igualmente correspondidas, y de la veintena aducida algo menos de la mitad se corresponden con visitas de altos cargos omanís a España, como la del exministro de Comercio e Industria en 2010, las dos visitas del ministro delegado de Defensa, la visita del ministro de Transportes y Comunicaciones en 2013 o la visita del Consejero Delegado del Fondo Soberano omaní en 2014.

Estas excelentes relaciones institucionales no sólo se han plasmado en visitas y viajes de altos cargos, sino que además han servido para ahondar en la colaboración entre ambos países (en julio de 2013 España y Omán firmaron un Memorando de Entendimiento cuyo objetivo es promover el desarrollo de las relaciones de amistad y de cooperación a través de unas consultas periódicas entre ambos países), para acordar un convenio que evite la doble imposición (CDI firmado ad referendum en abril de 2014, en el marco de la visita oficial de SM el Rey), así como para la firma de tres Memoranda of Understanding (MoU) para cooperación en materia de transporte, de defensa y de turismo, respectivamente. Asimismo, estas reuniones propiciaron un viaje de la Oman Chamber of Commerce and Industry (OCCI) a España en diciembre de 2014, en el cual se firmó un convenio de colaboración con la Cámara de España, y en el marco de la visita del secretario de Estado de Comercio en abril de 2015, se firmó un MoU entre COFIDES y el Fondo Soberano omaní (SGRF) para la creación de un fondo conjunto de 200 millones de euros para apoyar la inversión e internacionalización de las empresas españolas.

Este amplio trabajo de refuerzo de las relaciones institucionales ha sido continuamente complementado con continuas actividades de promoción comercial coordinadas desde ICEX y la Oficina Económica y Comercial en Mascate, entre las que destaca, en primer lugar, la celebración del primer Encuentro Empresarial España-Omán celebrado en Mascate en 2010, que supuso la presentación oficial de la oferta española en el mercado omaní y el pistoletazo de partida al incremento de nuestra posición en el mercado omaní, certificada cinco años más tarde cuando ICEX organizó el I Foro de Inversiones y de Cooperación Empresarial España-Omán, en presencia del ministro de Comercio e Industria omaní y del consejero delegado del Fondo Soberano SGRF, y al que asisten más de doscientas personas en representación de más de cuarenta empresas españolas y las noventa principales compañías omanís. En este periodo, además, la Oficina Económica y Comercial de España mantuvo un contacto cercano y continuo con las empresas españolas, prestándoles más de $250 \triangleright$ 
servicios personalizados (las cuales valoraron como muy útil para su actividad — valoración media de 4,4 sobre 5-), respondiendo más de 900 consultas de los mismos y distribuyéndoles periódicamente información de interés del mercado omaní (más de 1.200 informaciones se hicieron llegar a las empresas españolas a través de los canales de ICEX y de la oficina). A su vez, se organizaron y coordinaron más de cuarenta actividades de promoción comercial entre las cuales se incluyen más de quince participaciones en ferias o seminarios (Spain Gourmet Week, GCC Rail and Metro Conference 2015, COMEX 2011, y varias ediciones de Oman Power and Water y de INFRAOMAN), así como más de veinte misiones comerciales directas con la participación de casi 150 empresas españolas. Las actividades no solo se desarrollaron en Mascate, sino que también se organizaron eventos de promoción y difusión en España (como la reunión de empresarios en 2013 en la sede de ICEX con ocasión de la visita del ministro de Transportes y Comunicaciones omaní; el seminario sobre oportunidades en Omán organizado por ICEX en 2014 con la intervención tanto del consejero económico y comercial como de altos representantes de la Autoridad de Duqm, y la participación de más de cincuenta empresas españolas; o las Jornadas CAPACITA sobre Oriente Medio de ICEX, en 2017, en torno a cinco sectores concretos y con la participación de los consejeros económicos y comerciales en Riad, Dubái, Mascate y Teherán), en Dubái (como las tres Jornadas INTEGRA organizadas por ICEX en 2014, 2015 y 2016 que reunieron en esta ciudad a los consejeros económicos y comerciales de España en el CCG, con las empresas que operan en la zona y con un amplio número de pymes en torno a mesas y reuniones $\mathrm{B} 2 \mathrm{~B}$ sectoriales relativas al sector del agua, de infraestructuras del transporte y de energía, respectivamente), o incluso online (más de cinco Jornadas CONECTA de ICEX conectaron virtualmente por videoconferencia a múltiples empresas en España con la Oficina de Mascate; el consejero emitió sus Consejos en un corto vídeo disponible en la web de ICEX $y$, asimismo, participó virtualmente en seminarios como el de infraestructuras ferroviarias en 2015 con difusión en toda España). Actividades dirigidas tanto a la remoción de obstáculos al comercio bilateral como a la organización de misiones inversas vinieron, además, a complementar el conjunto de actividades de refuerzo institucional y promoción descritos.

\section{Evolución de Omán y de las relaciones comerciales de España y Omán en el periodo descrito}

Tal y como se señala en el Informe Económico y Comercial (IEC) de la Oficina de Mascate $^{2}$, la estructura política omaní está diseñada en torno al actual sultán Qabús bin Said al-Said, quien accedió al poder hace ya 46 años. El Sultán es Jefe de Estado y Primer Ministro, además de ministro de Defensa, ministro de Economía y ministro de Asuntos Exteriores, aunque luego estos ministerios son dirigidos por «ministros delegados». El Sultán nombra libremente a los ministros del gabinete y al Consejo de Estado (Majlis al-Dawa). Existe también un Consejo Consultivo (Majlis al-Shura), elegido por sufragio universal desde 2004, que tiene capacidad de propuesta y cierto control sobre el Gobierno y el presupuesto. El periodo de gobierno del sultán Qabús $\triangleright$

2 http://www.icex.es/icex/es/navegacion-principal/todos-nuestrosservicios/informacion-de-mercados/paises/navegacion-principal/elmercado/estudios-informes/DOC2016659739. html?idPais=OM 
ha coincidido con una época de desarrollo sin precedentes, no sólo en el país, sino a nivel internacional, y así, en 2010, Naciones Unidas ${ }^{3}$ señaló a Omán como el país con el mayor progreso humano durante los anteriores cuarenta años.

Así, como también indica el informe, la principal actividad económica en Omán es la industria extractiva, en particular, la extracción de petróleo y gas natural, base de la economía omaní, que representó en 2016 el 34,1 por 100 del PIB (pero que tradicionalmente ha pesado la mitad del producto interior bruto). Sin embargo, las reservas de crudo omaní son relativamente menores que las de otros países de la región y, dadas las características geológicas del país, de más costosa extracción. Según datos de la publicación World Factbook de la CIA y del Banco Central de Omán, el país dispone de reservas por un total de 5.300 millones de barriles, en comparación con los 25.000 millones de barriles de Catar, los 104.000 millones de Kuwait o los 98.000 millones de Emiratos Árabes Unidos. Durante la década pasada el nivel de producción fue decayendo paulatinamente hasta que en 2007 comenzó a dar fruto el esfuerzo inversor del Gobierno en técnicas de recuperación de petróleo. En 2015 se superaron los 358 millones de barriles producidos al año, nivel por primera vez superior al máximo de producción que se obtuvo en 2000 , cuando se alcanzaron los 350 millones de barriles, y ha aumentado el coste marginal de producción, que llega ya a 20 dólares por barril (frente a 3 o 5 dólares en los otros países de la región). La producción anual de gas en 2015 fue de 39.801 millones de metros cúbicos, de la que el 18 por 100 está asociado a la extracción de petróleo.

3 United Nations Development Programme (UNDP) (2010), «The Real Wealth of Nations: Pathways to Human Development", publicado en Human Development Report 2010: 20th Anniversary Edition.
Según la CIA, Omán dispone de unos 688.100 millones de metros cúbicos de gas natural.

Este informe económico y comercial también señala que los ingresos procedentes de la explotación de hidrocarburos han permitido que Omán disponga de recursos para potenciar también el desarrollo del sector industrial y del sector servicios. Una gran parte de estos recursos se ha destinado, al igual que otros países de la región, a desarrollar el sector petroquímico. Asimismo, el descubrimiento de reservas de gas natural no sólo ha impulsado el desarrollo de la industria del gas natural licuado, sino que ha permitido el suministro a empresas radicadas en el país de un input industrial energético básico a un precio competitivo, repercutiendo en el crecimiento del sector manufacturero (principalmente en aquellas ramas más intensivas en uso de energía como la metalurgia y la petroquímica) y estimulando la inversión extranjera directa en el país.

Esta favorable base estructural facilitó que Omán mantuviera un ritmo de crecimiento real sostenido, en torno al 5 por 100, en la década previa a 2015, apoyado además por una política fiscal muy expansiva. Los presupuestos contemplaron un incremento del gasto de más del 75 por 100 entre 2011 y 2014, fruto no sólo de los importantes proyectos de desarrollo público en el país, sino por la introducción también, desde la Primavera Árabe en 2011, de medidas tales como el aumento de empleados públicos (más de 70.000 anunciados), el incremento salarial de estos, la introducción del subsidio de desempleo o el aumento de las pensiones, que redundaron todas en un mayor poder adquisitivo del omaní medio. Respecto a los ingresos públicos, estos se incrementaron gracias a la evolución del precio del petróleo hasta 2015, permitiendo financiar este incremento del gasto social, dando fuelle a esta política $\triangleright$ 
expansiva y manteniendo al mismo tiempo una posición presupuestaria equilibrada.

Igualmente, las exportaciones de petróleo y gas propiciaron que, hasta 2015, Omán haya sido un país ahorrador neto y que en la última década hubiera experimentado continuos superávits corrientes (10,2 por 100 del PIB en 2012; 6,7 por 100 en 2013 y 5 por 100 en 2014).

No obstante, desde mediados de 2014, el precio del petróleo se desploma, cayendo más de un 60 por 100 hasta 2016, y se produce un giro coyuntural de 180 grados que lleva a un descenso del PIB nominal de un 14 por 100 en 2015 (y del 9 por 100 en 2016). La caída de los precios del petróleo provoca una caída de las exportaciones superior al 33 por 100 y una reducción de los ingresos públicos en 2015 superior al 36 por 100 y del 15 por 100 en 2016, lo que conlleva que, a pesar de los esfuerzos iniciales por recortar el gasto, se termine 2015 con un déficit de más del 17 por 100 del PIB y 2016 con un déficit de más del 20 por 100 del PIB. En consecuencia, el sultanato está actualmente inmerso en un proceso de ajuste para reducir su dependencia del nuevo precio del petróleo.

Como se ha señalado, el potencial de Omán no sólo fue identificado por la Administración comercial española, sino reconocido también por Naciones Unidas en 2010 y desde 2008 el Sultanato ha vivido, como comentado, una época de fulgor económico, de la que España ha conseguido participar, como se podrá ver a continuación.

Las relaciones comerciales bilaterales entre Omán y España son aún relativamente modestas, ya que hay que tener en cuenta que, como indica el IEC, aparte del sector de hidrocarburos, el mercado omaní es pequeño y su área de influencia comercial es principalmente el Océano Índico y el Sudeste Asiático. Con todo, como se puede ver en el Cuadro 1, la evolución del comercio bilateral ha sido extremadamente positiva para España desde 2009, primer año de entrada en vigor del PIDM del CCG y de apertura de la Oficina Económica y Comercial en Mascate. Concretamente, la comparación del periodo de siete años anterior a este hecho con el periodo, también de siete años posterior, muestra que las exportaciones españolas casi se sextuplicaron (crecimiento del 484,9 por 100, pasando de 393,9 millones de euros a 2.303,7 millones) en el reciente septenio, mientras que las importaciones se redujeron un 8,1 por 100 en el segundo periodo, por lo que se pasó de un saldo deficitario para España en los siete años anteriores a 2009 de 564,1 millones de euros a un saldo fuertemente superavitario de 1.423,3 millones de euros, lo que supone que la tasa de cobertura aumentó desde el 41 hasta el 262 por 100.

Este éxito de las exportaciones españolas es todavía más evidente cuando se compara con la evolución del conjunto de las $\triangleright$

CUADRO 1

RELACIONES COMERCIALES ESPAÑA-OMÁN

(En miles de euros)

\begin{tabular}{|c|c|c|c|c|}
\hline & 2001-2008 & 2009-2016 & Variación & Variación comercio España \\
\hline Exportaciones & 393.864 & 2.303 .669 & $484,9 \%$ & $41,8 \%$ \\
\hline Importaciones & 957.937 & 880.406 & $-8,1 \%$ & $12,6 \%$ \\
\hline Saldo & -564.072 & 1.423 .263 & $-352,3 \%$ & $-52,6 \%$ \\
\hline Tasa cobertura & $41 \%$ & $262 \%$ & $536,4 \%$ & $25,9 \%$ \\
\hline
\end{tabular}




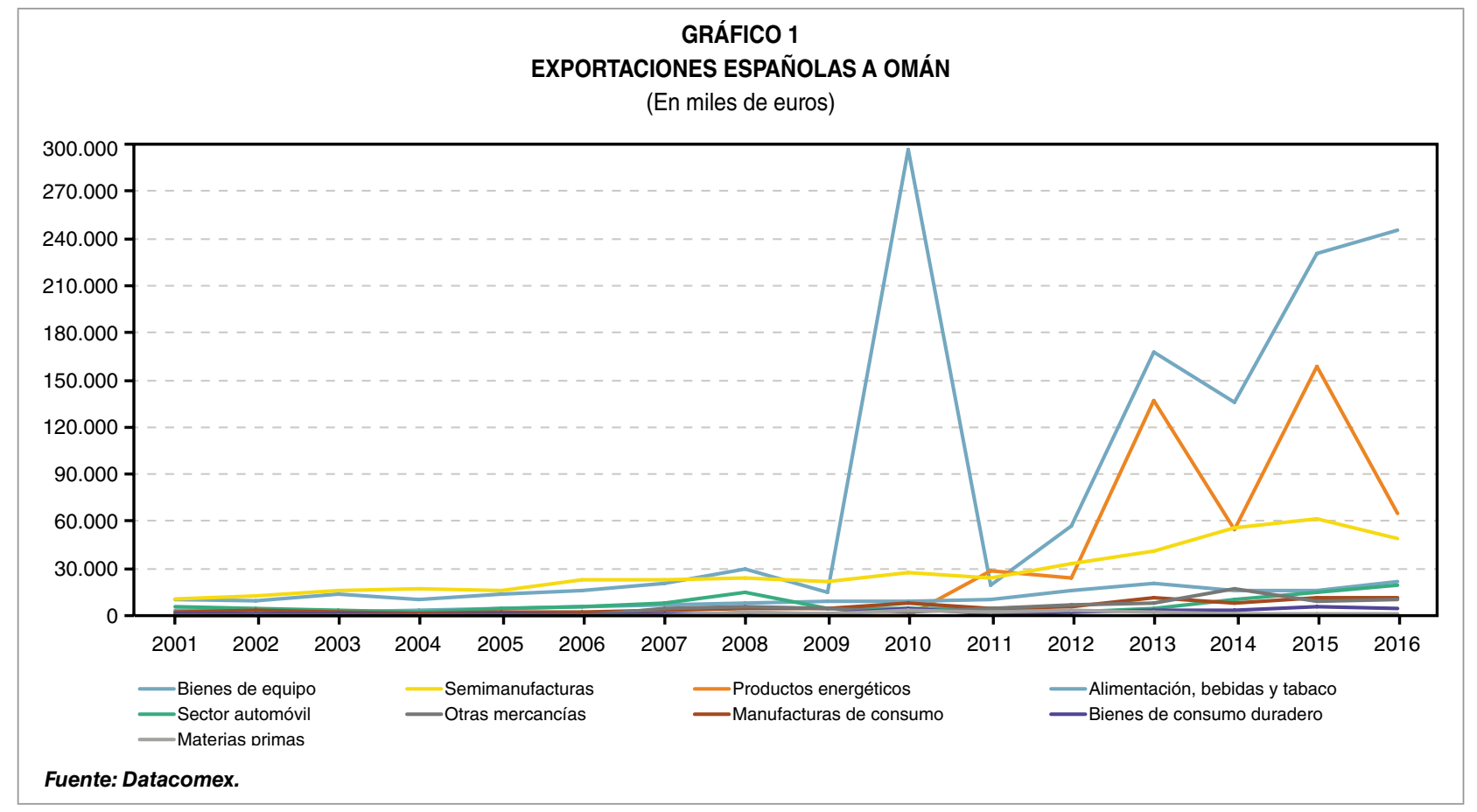

exportaciones españolas al mundo, que entre ambos septenios aumentaron un 41,8 por 100 (frente al 484,9 por 100 mencionado), y este mayor dinamismo de las exportaciones españolas al Sultanato conllevó, por un lado, a una fuerte escalada de Omán en el ranking de clientes de los productos españoles: de ocupar el puesto 93 en el año 2007 pasó a situarse como el 57. país en la lista de países importadores de bienes españoles; $y$, por otro lado, ha propiciado que Omán se haya situado como el tercer cliente de España en la Península Arábiga (por detrás tan sólo de Emiratos Árabes Unidos y Arabia Saudí), manteniendo una cuota del 8,1 por 100 de las exportaciones españolas a la zona en 2016, frente al 6,3 por 100 en 2014, o el 2,6 por 100 en 2009, cuando Omán ocupaba el quinto puesto en el ranking de destinos de las exportaciones en la Península.

Un análisis por sectores de esta espectacular evolución muestra que la mayor parte de este éxito se debe a la evolución de las exportaciones de bienes de equipo, productos energéticos y semimanufacturas, en línea con el intenso proceso de desarrollo del país, y en parte arrastradas por las múltiples licitaciones públicas ganadas por empresas españolas, como veremos más adelante.

Asimismo, en cuanto a las relaciones de inversión bilaterales, cabe destacar que Omán es actualmente el $511^{\circ}$ país inversor (en términos de inversión directa extranjera) en España desde 1993, y el Sultanato en 2016 ocupó el puesto $40 .-$ como destino de los flujos de inversión directa española en ese año. Por su parte, en cuanto a la inversión española en Omán, Unión Fenosa Gas ${ }^{4}$ se incorporó en el año 2004 a Qalhat LNG con una participación del 7,36 por 100 y tiene firmados contratos de suministro con Qalhat LNG a 20 años tras la inauguración, en 2006, del tercer tren de licuefacción en Sur; y que $\mathrm{CLH}^{5}$ y la empresa local que posee y gestiona las refinerías de Omán, ORPIC, se $\triangle$

4 http://www.gasnaturalfenosa.com/es/actividades/presencia+ en+el+mundo/asia+y+oceania/1285338593736/oman.html

5 http://www.clh.es/revistasclh/Numero_33/html/04.htm 
asociaron para encargarse del diseño y construcción de nuevas redes de oleoductos multiproductos, un centro de almacenamiento y su conexión con la nueva terminal aeroportuaria.

Pero el éxito español en este país no se circunscribe sólo a las exportaciones e inversiones, sino que España ha tenido un éxito sobresaliente en la participación de las licitaciones públicas que el Gobierno omaní ha lanzado en este periodo, lo que ha llevado a que, si bien en 2008 sólo hubiera dos empresas españolas instaladas tras ganar licitaciones en Omán, en 2012 este número había aumentado a ocho y cuatro años más tarde, en 2016, se superaba la treintena de empresas españolas que han conseguido contratos en el país por un importe superior a los 4.000 millones de euros en conjunto. Estas empresas se hicieron con importantes operaciones en los sectores que había identificado el PIDM. Así, por ejemplo:

En el campo del petróleo y el gas, el sector preferente del país, Técnicas Reunidas, se adjudicó, en agosto de 2017, el primer y principal paquete para la construcción de la Refinería de Duqm $^{6}$, después de haber conseguido varios contratos menores en el Sultanato7,8; $\mathrm{OHL}$ Industrial, en joint venture con SENER, se adjudicó en 2014 una licitación de la empresa de hidrocarburos local, PDO, para una planta demaximización de recuperado de condensados en las instalaciones de dos plantas de tratamiento de gas; Tradebe se adjudicó en 2015 un contrato con la principal empresa de petróleo local, PDO, para la gestión de residuos; y TECNA se adjudicó, en concurso internacional de la Oman Gas Company (OGC),

\footnotetext{
6 http://www.tecnicasreunidas.es/recursos/noticias/tr-ir-duqm.pdf

7 http://www.tr-engineering.com/project-news

8 http://www.link2.es/tr/es/planta-de-tratamiento-de-aguasresiduales-de-darsait-y-estacion-de-bombeo-de-auzaibah/

http://www.link2.es/tr/es/saih-rawl-central-de-ciclo-abierto/

http://www.link2.es/tr/es/estacion-de-bombeo-y-sistema-de-retornoen-el-area-industrial-del-puerto-de-sohar-swips-iil
}

la ingeniería conceptual para la extracción de gases licuados del petróleo (LPG), en la red de gasoductos de Salalah al Sur de Omán y, en 2015, se adjudicó el contrato de director de dicho proyecto.

Asimismo, España ha compartido su experiencia en infraestructuras del transporte y Ferrovial ${ }^{9}$ se adjudicó, en agosto de 2013, el paquete 5 del proyecto de autopista de Batinah; Isolux ${ }^{10}$ se adjudicó, en febrero de 2014 , la dualización de una sección de la carretera BidbidSur; e INECO se ha adjudicado en Omán un contrato con el Ministerio de Transportes y Comunicaciones para el estudio del transporte en la ciudad de Mascate, y otro para la consultoría sobre el sistema de autobuses ${ }^{11}$ (asimismo, en 2015, se había adjudicado en asociación con Técnicas Reunidas el contrato para la dirección del proyecto entero del ferrocarril en Omán, sin embargo, este proyecto se ha cancelado).

Pero quizás donde España ha mostrado más su liderazgo ha sido en el terreno de las utilities (agua, electricidad, residuos...), ya que Cadagua $^{12}$, por ejemplo, construyó la planta de desalación en Al Gubrha y está encargada del diseño y construcción de la nueva planta de tratamiento de aguas residuales de Darsait; Abeinsa ${ }^{13}$ construyó una planta desaladora con tecnología de osmosis inversa con capacidad para tratar $45.000 \mathrm{~m}^{3}$ al día en Barka; $\triangleright$

\footnotetext{
9 http://www.ferrovial.com/es/prensa/notas_prensa/ferrovialconstruira-tramo-autopista-une-oman-emiratos-arabes-260-milloneseuros/

10 http://www.isoluxcorsan.com/es/comunicacion/notas-de-prensal isolux-corsan-ejecutara-la-ampliacion-y-mejora-de-una-autopista-enoman.html

11 https://www.ineco.com/webineco/en/communication/latest-news/ new-contract-oman-engineering-firm-ineco

12 http://www.cadagua.es/noticias-novedades/la-desaladora-de-alghubrah-ya-suministra-agua-a-la-red-publica-de-abastecimiento-en-oman http://www.cadagua.es/proyectos-singulares/planta-tratamientoaguas-residuales-de-darsait

13 http://www.abeinsa.com/web/es/nuestras_actividades/ingenieria_ y_construccion/agua_medioambiente/desalacion/proyectos/Desaladora DeBarka.html
} 
Valoriza $^{14}$ se adjudicó en 2015 el proyecto de construcción, operación y mantenimiento de una planta de desalación de agua también en Sohar de $250.000 \mathrm{~m}^{3} / \mathrm{d}$; Elecnor ${ }^{15}$ se adjudicó en julio de 2015 unas canalizaciones de agua en Qurayat y en 2017, la instalación de paneles solares en la sede de la empresa omaní de hidrocarburos PDO; TSK ${ }^{16}$ ha conseguido recientemente la adjudicación de la empresa Masdar para la ingeniería, aprovisionamiento y construcción para el primer gran parque eólico en Omán (50 MW) en la región de Dhofar; Inabensa se adjudicó en diciembre de 2014 la construcción de una estación eléctrica en Ibri de 132/133kv y la línea de transmisión, y en marzo de 2016 se ha adjudicado la estación 132/133kv y la línea de transmisión de Sinaw; Urbaser, por su parte, se adjudicó un contrato para la recogida de basuras en la región de South Batinah.

Y, por supuesto, España ha mostrado su capacidad como proveedor de tecnología y de productos y servicios de alto valor añadido, y así, Airbus Military firmó en mayo de 2012 la venta de ocho aviones militares C295; Indra ${ }^{17}$ ha desarrollado el proyecto de instalación, testeo y puesta en marcha de sistemas de tráfico aéreo en los aeropuertos de Mascate y Salalah y tiene el encargo de extender el proyecto a todos los aeropuertos comerciales en Omán, $y$, asimismo, colabora con el Ministerio de Defensa del Sultanato de Omán para suministrarle un sistema integrado de vigilancia y defensa aérea; Rodman ${ }^{18}$ vendió, en julio de

\footnotetext{
14 http://www.valoriza-agua.com/ES_EN/Sala-de-prensa/ultimasnoticias/noticia.aspx?C=tcm:20-25518\&P=1

15 https://www.elecnor.es/Common/pdf/galerias_descargas/ infraestructuras/agua/Ficha-Red-transporte-agua-Qurayyat-Oman.pdf

16 http://www.grupotsk.com/noticias/tsk-construira-el-mayorparque-eolico-del-golfo

17 http://www.indracompany.com/es/noticia/tecnologia-indramultiplica-capacidad-gestion-trafico-aereo-oman

18 https://rodman.es/es/rodman-news/noticias/rodman-construirapatrulleras-para-la-policia-de-oman
}

2015, cinco patrulleras de intervención a la policía de Omán; AMPO ${ }^{19}$ consiguió en 2017 el contrato para suministro de válvulas industriales para el emblemático proyecto omaní LIWA Plastics Industries Complex Project en Sohar y Acciona Producciones y Diseño ${ }^{20}$ se adjudicó, en 2013, la licitación para el acondicionamiento del Museo Nacional.

Además, este éxito de las empresas españolas, en el mercado omaní ha ayudado a dar a conocer y reforzar la imagen de España en los sectores en que es líder, más allá de los sectores con los que el público omaní aún relacionaba a España en 2010 (turismo, pesca, deportes...).

\section{Conclusiones}

La Administración comercial española se embarcó allá por 2004 en un ejercicio estratégico de identificación y desarrollo de planes de actuación para unas áreas que, en base a un exhaustivo análisis económico, se consideraban que podrían ser de interés para la internacionalización de la empresa española, entre las cuales se encontraba el Consejo de Cooperación del Golfo, en el que se integra el Sultanato de Omán, y en cuya capital se decidió instaurar una Oficina Económica y Comercial para dar seguimiento al planteamiento estratégico.

Como se ha podido observar, la apuesta por este mercado no sólo parece resultar acertada, a tenor de los datos expuestos del país en los años posteriores, sino que el éxito tanto de las exportaciones como de las inversiones $y$, sobre todo, de las licitaciones en sectores clave $\square$

\footnotetext{
19 http://ampo.com/es/ampo-foundry-suministra-100-componentespara-bombas-en-material-superduplex-para-una-planta-desalinizadoraen-oman/

20 http://www.acciona-apd.com/?tag=oman
} 
adjudicadas a empresas españolas, parece sugerir que el ejercicio previo de intentar identificar países en los que se diera el trinomio de (i) país con buenas perspectivas económicas, (ii) en el que las empresas españolas estén infrarrepresentadas (o tengan amplio potencial de recorrido al alza) y (iii) además sea en sectores que coincidan con la oferta española ha sido un éxito para el caso aquí estudiado.

Con todo, cabe reconocer que, actualmente, Omán se encuentra en una coyuntura muy distinta, y esto a buen seguro afectará (está afectando ya) en el corto plazo a la línea emprendida por las empresas españolas, pero los éxitos cosechados hasta ahora, más las externalidades positivas generadas (en términos de imagen, de economías de escala en el proceso de internacionalización en la zona o de referencias nuevas para las empresas en sus procesos de licitación) y las expectativas de que el Sultanato en el medio plazo recobre el vigor hacen que el análisis coste-beneficio de esta iniciativa de la Administración española haya sido muy rentable, y la consecución de los objetivos que inicialmente se marcaron se ha conseguido holgadamente.

\section{Bibliografía}

[1] PÉREZ RAPOSO Y CERNO (2011). «Las relaciones comerciales de España con los países objeto de los Planes Integrales de Desarrollo de Mercados (PIDM) 1999-2010». Revista ICE, n.ㅇ 859.

[2] SUBDIRECCIÓN GENERAL DE ANÁLISIS Y ESTRATEGIA (2005). "Metodología de la Secretaría de Estado de Turismo y Comercio para la selección de mercados prioritarios". Boletín Económico de ICE, n.․ 2.836.

[3] UNITED NATIONS DEVELOPMENT PROGRAMME (UNDP) (2010). «The Real Wealth of Nations: Pathways to Human Development». Human Development Report 2010: 20th Anniversary Edition. 